\title{
Mortality during hospitalisation for pneumonia in Alberta, Canada, is associated with physician volume
}

\author{
T.J. Marrie*, K.C. Carriere", Y. Jin", D.H. Johnson ${ }^{+}$
}

Mortality during hospitalisation for pneumonia in Alberta, Canada, is associated with physician volume. T.J. Marrie, K.C. Carriere, Y. Jin, D.H. Johnson. C) ERS Journals Ltd 2003.

ABSTRACT: The association of mortality with patient factors (severity of illness, comorbidity), physician factors (specialty training, prehospitalisation visit, in-hospital consultation, volume of patients seen per physician) and healthcare organisation factors (patient-travel distances, regional beds per capita, admitting hospital-bed occupancy, admitting hospital-bed turnover, hospital location, volume of pneumonia cases per hospital) after hospital admission with community-acquired pneumonia was investigated using administrative data from Alberta, Canada from April 1, 1994-March 31, 1999.

During the 5-yr study period there were 43,642 pneumonia hospitalisations, with an $11 \%$ in-hospital and $26 \%$ 1-yr mortality. Patient severity of illness and comorbidity were the strongest predictors of increased mortality. Physicians with the highest inhospital pneumonia patient volume $\left(>27\right.$ patients $\left.\cdot \mathbf{y r}^{-1}\right)$ cared for patients with greater severity/comorbidity, but with decreased odds of in-hospital mortality, compared with the lowest volume physicians (less than seven patients per year).

The effects of internal medicine specialist or subspecialist care were mixed, with a reduction in deaths for the first $72 \mathrm{~h}$ and an increase in in-hospital deaths. Prehospitalisation visit by a physician was associated with decreased mortality. Healthcare organisation factors were the least strong predictor of mortality, demonstrating an effect only for 1-yr mortality in those discharged alive from hospital. Admissions to larger volume or metropolitan hospitals were associated with a decrease in mortality.

Severity of illness and comorbidity had the strongest association with mortality. The first association of high-volume physician and pre-hospital care with decreased inhospital mortality for community-acquired pneumonia is reported. Eur Respir J 2003; 22: 148-155.
*Dept of Medicine, ${ }^{\#}$ Dept of Mathematical and Statistical Sciences and ${ }^{+}$Dept of Critical Care Medicine, University of Alberta, and Information Analysis, Alberta Health and Wellness, Alberta, Canada.

Correspondence: D. Johnson

$368 \mathrm{O}^{\prime}$ Connor Close

Edmonton

Alberta T6R 1L4

Canada

Fax: 17804359083

E-mail: cujecjohnson@shaw.ca

Keywords: Community-acquired pneumonia health-service utilisation

physician practice

Received: December 122002

Accepted after revision: February 282003

This work was partially supported by the Alberta Center for Health Service Utilisation Research.
Community-acquired pneumonia (CAP) is a common reason for hospital admission [1, 2]. Algorithms to help clinicians decide upon hospital admission and discharge have been devised, validated and published [2-6]. These guidelines are robust and may decrease mortality [7, 8]. Despite clinical guidelines, considerable variation exists in the treatment of CAP within larger Canadian hospitals [9]. The Healthcare Financing Administration stated that peer-reviewed organisations also documented variations in the processes of care for hospitalised CAP [10] that directly impacted upon patient outcome [11, 12]. All these studies address quality-of-care issues at the level of the clinician-patient interaction. There are few studies of healthcare system factors that are associated with different mortality outcomes in hospitalised pneumonia patients.

This study attempts to quantify the relative strength of associations between mortality for hospitalised CAP and patient factors (severity of illness, comorbidity), physician factors (specialty training, pre-hospitalisation visit, in-hospital consultation, volume of patients seen per physician), and healthcare organisation factors (patient travel distances, regional beds per capita, admitting hospital-bed occupancy, admitting hospital-bed turnover, hospital location, volume of pneumonia cases per hospital, season/day/time of admission). The association of all these factors to in-hospital mortality and 1-yr mortality for hospital survivors is described. Administrative data from April 1, 1994-March 31, 1999 was used to study the entire scope of rural and urban hospital practice in one Canadian province.

\section{Methods}

\section{Defining pneumonia and data extraction}

Health-service databases used included the following: 1) Canadian Institute for Health Information's (CIHI) Inpatient Discharge Abstract Database (DAD) for the province of Alberta for 1994-1995 to 1998-1999; 2) Alberta Physician Claims Assessment System Database for 1994-1995 to 1999-2000; and 3) Alberta Health Insurance Plan Registry File for 19942000. The analysis was performed within the protected environment of Alberta Health and Wellness, which is governed by provincial legislative guidelines on the confidentiality of health information. These data capture nearly the entire population and included a unique, anonymous personal identifier allowing linkage between databases.

Inclusion criteria were CAP, defined as the most responsible diagnosis (MRD) or any of the other 15 diagnosis codes defined to be type 1 (the diagnosis existed prior to admission) with the International Classification of Disease, ninth revision (ICD-9), Clinical Modification (CM) values of 480-487.x 
(pneumonia) or 507.x (aspiration pneumonia), excluding 484.x (pneumonia of infectious diseases classified elsewhere) found in CIHI DAD [13, 14].

Exclusion criteria included: 1) not an Alberta resident or not treated in an Alberta acute-care facility; 2) an adjacent diagnosis with hospitalisation for a surgical procedure; and 3) any previous hospitalisation $<10$ days since incident pneumonia case.

Physician visits for CAP were extracted from the Alberta Physician Claims Assessment System Database. Physician visits were defined as consultation claims (Canadian Classification of Procedures (CPX) 03.x) for any diagnosis 2-14 days prior to admission date [15]. The MRD was classified as CAP (as defined above), any respiratory diagnosis (ICD-9CM 460-519.9, excluding pneumonia), or any other diagnosis. All physician characteristics were extracted from hospital abstracts.

\section{Patient factors}

Recorded demographical and comorbidity factors included the following: 1) age (18-44, 45-64, 65-74, 75-84, or $\geqslant 85$ yrs (age at the fiscal year end is used )); 2) sex; 3) aboriginals registered with the Dept of Indian Affairs and Northern Development, recorded within the Alberta Healthcare Premium Registry databank; 4) urban or nonurban region of residence; and 5) Charlson's comorbidities, extracted using Deyo's criteria and each of the 12 diagnostic categories compiled as none, one, two and more than two [16, 17].

Recorded severity-of-illness factors included the following: 1) transfer to hospital from a nursing home, long-term care or continuing-care institution; 2) transfer to hospital by ambulance as defined in hospital abstract; 3) admission from emergency room as defined in hospital abstract; 4) emergent admission from home/office/clinic as defined in hospital record abstract; 5) special (intensive) care unit admission (as defined by each hospital); 6) diagnosis code of respiratory failure or arrest (ICD-9-CM 518.81, 799.1); 7) diagnosis code of hypotension or shock (ICD-9-CM 458.xx, 758.5x); 8) procedure code for ventilation $>96 \mathrm{~h}$ (ICD-9-CM 96.72); and 9) procedure code for dialysis (ICD-9-CM 39.95, 54.98). Severity of presentation was defined as any one of special-care unit admission, hypotension/shock, in-hospital dialysis, respiratory arrest/failure or ventilation for $>96 \mathrm{~h}$.

Physician factors included the following: 1) general/family practitioner listed as most responsible hospital physician; 2) any internal medicine specialist or subspecialist listed as consultation physician; 3) annual volume of pneumonia cases per physician (by quartile rank), including any hospital consultations and most responsible hospital physician; 4) pre-admission ambulatory visit (physician claims CPX 03.x) by any physician 2-14 days prior to admission date with the diagnosis code for pneumonia as defined above; 5) preadmission ambulatory visit (physician claims CPX 03.x) by an internal medicine specialist 2-14 days prior to admission date with the diagnosis code for pneumonia as defined above; and 6) any emergency room visit 2-14 days prior to admission date with the diagnosis code for pneumonia as defined above. Physician specialty was coded in the hospital abstract.

Healthcare organisation factors included the following: 1) admission to a hospital not within the patient's defined health region of residence (see below); 2) transfer from a smaller to a larger acute-care facility (see below) for the diagnosis of pneumonia as defined above; 3) remote distance to hospital (see below); 4) hospital volume (see below); 5) hospital beds per capita in the hospital's health region (all active acute-care hospital beds in each year per health region were surveyed and maintained in the provincial databases); 6) bed turnover defined as the ratio of all hospital admissions per hospital bed in the specific hospital on the date of pneumonia admission; 7) occupancy rate defined as the daily census per hospital bed in the specific hospital at the date of pneumonia admission; 8) weekend (Saturday/Sunday/statutory holiday) admission date; 9) admission time 18:00-08:00 h; and 10) admission in December 1-March 31 (peak season for pneumonia hospital admissions in Alberta).

\section{Derived variables}

Defining hospital type by patient volume. All hospitals in Alberta are administered by an autonomous regional board in each of the 17 health regions. All 3 million residents of Alberta are enrolled in the public healthcare insurance plan and reside in one of the 17 health regions. Hospitals admitting patients with CAP were categorised into five groups on the basis of the average number of hospital discharges per year over the 5-yr study period, geographic location and medical-school proximity.

Rural hospitals included 77 hospitals with $<50$ cases $\mathrm{yr}^{-1}$ and 27 hospitals with $50-108$ cases $\cdot \mathrm{yr}^{-1}$. The rural hospital cut-off values for pneumonia cases of 50 and 108 represented the 50th and 75th percentiles. Regional hospitals included five hospitals located in one of the five nonmetropolitan, regional, healthcare cities with 67-251 cases $\mathrm{yr}^{-1}$, and one high-volume rural hospital with 221 cases $\cdot \mathrm{yr}^{-1}$. Metropolitan hospitals included seven hospitals located in the metropolitan health regions of Calgary and Capital hospitals with 92-813 cases. $\mathrm{yr}^{-1}$ and two hospitals located adjacent to medical schools; one hospital in each of two metropolitan centres with 493 and 610 cases $\cdot \mathrm{yr}^{-1}$.

Calculating remote distance to hospital. Each separation was mapped to the centre of a postal code and the distance "as the crow flies" between centroids calculated. Nearest hospital distance to resident postal code was obtained for all nonurban residents. Urban resident distances were zero. Distances $>50 \mathrm{~km}$ were defined as remote.

Mortality. Vital-statistics declaration of death certificates were merged with the Alberta Healthcare Premium Registry databank in order to determine deregistration from the plan. Reliability of linkage was high (99.5\%), verified by comparing in-hospital deaths, recorded by hospital-chart extraction, to Alberta Healthcare Premium Registry death, derived from vital statistics.

Outcomes used in regressions included the following: 1) inhospital death per hospital discharge within the first $72 \mathrm{~h}$ of admission; 2) in-hospital mortality per hospital discharge; and 3) 1-yr mortality per hospital discharge in those not dying in hospital.

\section{Statistics}

A forward, stepwise selection of factors was used to determine the order of importance of the factor influencing mortality. The factors were grouped as patient severity of illness and comorbidity group, healthcare organisation group or physician group. Each entire factor group was also sequentially forced in the model and the c-statistic determined. The c-statistic is a summary-rank correlation statistic between the observed responses and predicted probabilities that equals the area under the receiver-operator curve and is commonly reported for risk-adjustment models [18].

The unit of analysis was hospital discharge, with some 
patients being hospitalised on multiple occasions per year. The authors attempted to adjust for correlations in hospital discharges within the same subject, but it did not result in a substantial difference from those under the assumption of zero correlation. Therefore, the authors opted to report results of a simpler approach based on multiple logistic models [19, 20]. To control the large-sample size effect on statistical significance, a one-third random sample from the hospital discharge data was used for statistical modelling [21]. The results were validated with the entire data set to test for bias in the sample. Significance was defined as $\mathrm{p}<0.05$.

\section{Results}

During the 5 yrs of the study there were 43,642 acute-care pneumonia hospital discharges. The in-hospital mortality per hospital discharge was $11 \%(9.2 \%$ in the first 24 days as shown in figure 1) and the overall 1-yr mortality per hospital discharge was $26 \%$. Of 4,693 in-hospital deaths, $11.5 \%$ (538) died within $24 \mathrm{~h}$ of admission, $16.5 \%$ (773) within $25-72 \mathrm{~h}$ of admission, $45.0 \%(2,111)$ within 73 h to 2 weeks of admission and $27.1 \%(1,271)$ died $>2$ weeks after admission.

Mortality (table 1) was proportionally higher in males, older patients, those of urban residence and those with comorbidity (in particular malignancy, congestive heart failure, vascular diseases, dementia and renal disease; these data not shown). The severity-of-illness markers identified proportionally higher mortality, except for seasonal admissions (table 2). Severity of illness tended to be greater for deaths within $72 \mathrm{~h}$ compared with all in-hospital deaths. Mortality was proportionally greater in urban hospitals and hospitals with

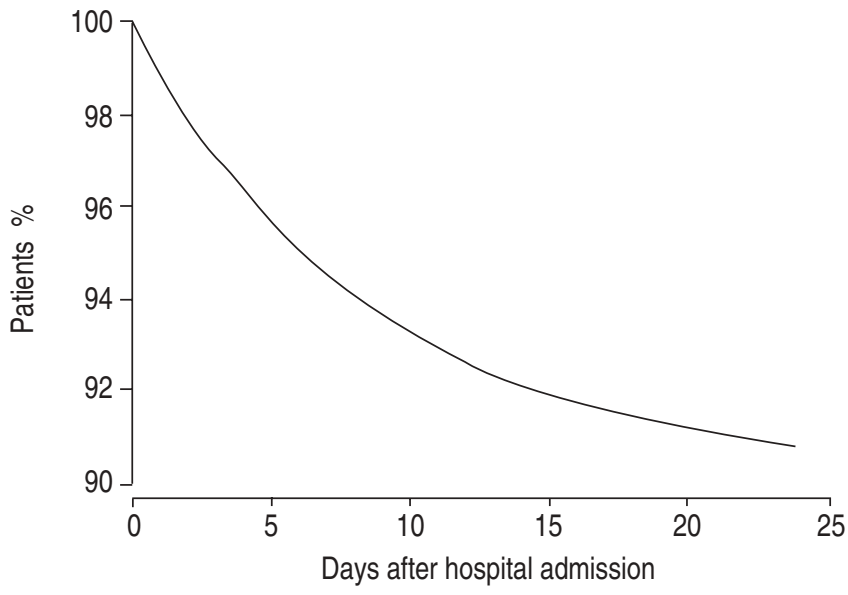

Fig. 1. - In-hospital survival for community-acquired pneumonia.

proportionally greater mortality were located closer to patients' home residences (table 3 ). The median daily hospital occupancy rate was $75 \%$ (interquartile range $56-90 \%$ ). The median number of daily admission per bed was $0.15(0.1-0.2)$. Mortality was proportionally greater when internal medicine specialists/subspecialists were involved in care, either as the most responsible physician or consultant (table 4). Only 5\% of patients had a most responsible physician that was neither a general/family practitioner nor an internal medicine specialist/ subspecialist.

The mean number of hospitalised CAP patients per most responsible unique physician was 7.4 patients $\cdot \mathrm{yr}^{-1}$. These were

Table 1. - Patient demographical and comorbidity factors for hospitalised community-acquired pneumonia in Alberta during April 1, 1994-March 31, 1999

\begin{tabular}{lcccc}
\hline Characteristics & $\begin{array}{c}\text { All pneumonia } \\
\text { hospital discharges }\end{array}$ & $\begin{array}{c}\text { First 72-h mortality } \\
\text { for pneumonia } \\
\text { hospital discharges }\end{array}$ & $\begin{array}{c}\text { All in-hospital mortality } \\
\text { for pneumonia } \\
\text { hospital discharges }\end{array}$ & $\begin{array}{c}\text { All-cause 1-yr mortality } \\
\text { for pneumonia } \\
\text { hospital discharges }\end{array}$ \\
\hline Patients $\mathrm{n}$ & 43642 & 1311 & 4693 & 11370 \\
$\begin{array}{l}\text { Female } \\
\text { Age yrs }\end{array} \quad 21070(48.3)$ & $544(41.5)$ & $1954(41.6)$ & $4633(40.7)$ \\
$\quad$ Mean \pm SD & $65.86 \pm 19.70$ & $75.53 \pm 15.12$ & $76.43 \pm 13.99$ & 79 \\
$\quad$ Median & 71 & $79(3.1)$ & $105(2.3)$ & $75.64 \pm 13.99$ \\
Aboriginal treaty status & $2966(7.0)$ & $716(54.6)$ & $2665(56.8)$ & 78 \\
Metropolitan region of residence & $18433(42.2)$ & $1.64 \pm 1.21$ & $1.87 \pm 1.23$ & $5837(51.3)$ \\
Comorbidity mean \pm SD & $1.06 \pm 1.10$ & & & $1.71 \pm 1.20$ \\
\hline
\end{tabular}

Data are presented as $\mathrm{n}(\%)$, unless otherwise stated.

Table 2. - Severity of illness for hospitalised community-acquired pneumonia in Alberta during April 1, 1994-March 31, 1999

\begin{tabular}{|c|c|c|c|c|}
\hline Illness factors & $\begin{array}{l}\text { All pneumonia } \\
\text { hospital discharges }\end{array}$ & $\begin{array}{l}\text { First } 72 \text {-h mortality } \\
\text { for pneumonia } \\
\text { hospital discharges }\end{array}$ & $\begin{array}{l}\text { All in-hospital mortality } \\
\text { for pneumonia } \\
\text { hospital discharges }\end{array}$ & $\begin{array}{c}\text { All-cause 1-yr mortality } \\
\text { for pneumonia } \\
\text { hospital discharges }\end{array}$ \\
\hline Patients n & 43642 & 1311 & 4693 & 11370 \\
\hline Transfer from continuing care institution & $4422(10.1)$ & $367(28.0)$ & $1032(22.0)$ & $2366(20.8)$ \\
\hline Transfer to a larger acute hospital ${ }^{\#}$ & $531(1.4)$ & N/A & N/A & $173(2.5)$ \\
\hline Transfer to hospital by ambulance & $12370(28.3)$ & $743(56.7)$ & $2434(51.9)$ & $4974(43.7)$ \\
\hline Weekend/holiday admission & $12113(27.8)$ & $427(32.6)$ & $1401(29.9)$ & $3216(28.3)$ \\
\hline Admission 18:00-08:00 h & $18759(43.0)$ & $605(46.1)$ & $2126(45.3)$ & $4979(43.8)$ \\
\hline Admission December 1-March 31 & $18884(43.3)$ & $553(42.2)$ & $1924(41.0)$ & $4607(40.5)$ \\
\hline Admission from emergency room & $14846(34.0)$ & $444(33.9)$ & $1639(34.9)$ & $4014(35.3)$ \\
\hline $\begin{array}{l}\text { Emergent admission defined } \\
\text { in hospital record abstract }\end{array}$ & $12514(28.7)$ & $537(41.0)$ & $1755(37.4)$ & $3628(31.9)$ \\
\hline Severity of presentation & $5322(12.2)$ & $514(39.2)$ & $1610(34.3)$ & $2420(21.3)$ \\
\hline
\end{tabular}

Data are presented as $\mathrm{n}(\%)$, unless otherwise stated. ${ }^{*}$ : excluding those that died in hospital; ${ }^{\circ}$ : defined in methods. 
Table 3. - Hospital factors for community-acquired pneumonia in Alberta during April 1, 1994-March 31, 1999

\begin{tabular}{|c|c|c|c|c|}
\hline Hospital factors & $\begin{array}{l}\text { All pneumonia } \\
\text { hospital discharges }\end{array}$ & $\begin{array}{l}\text { First } 72 \text {-h mortality } \\
\text { for pneumonia } \\
\text { hospital discharges }\end{array}$ & $\begin{array}{c}\text { All in-hospital mortality } \\
\text { for pneumonia } \\
\text { hospital discharges }\end{array}$ & $\begin{array}{c}\text { All-cause 1-yr mortality } \\
\text { for pneumonia } \\
\text { hospital discharges }\end{array}$ \\
\hline Patients $n$ & 43642 & 1311 & 4693 & 11370 \\
\hline $\begin{array}{l}\text { Patient residence region } \\
\text { different from hospital }\end{array}$ & $5247(12.0)$ & 177 (13.5) & $510(10.9)$ & $1387(12.2)$ \\
\hline $\begin{array}{l}\text { Remote distance to local hospital } \\
\text { Hospital }\end{array}$ & $478(1.1)$ & $3(0.2)$ & $11(0.2)$ & $57(0.5)$ \\
\hline \multicolumn{5}{|l|}{ Rural } \\
\hline$<50$ cases $\cdot \mathrm{yr}^{-1}$ & $9136(20.9)$ & $183(14.0)$ & $78(12.3)$ & $1841(16.2)$ \\
\hline $50-108$ cases $\cdot \mathrm{yr}^{-1}$ & $9367(21.5)$ & $214(16.3)$ & $702(15.0)$ & $1973(17.4)$ \\
\hline Regional & $5828(13.4)$ & 167 (12.7) & $657(14.0)$ & $1482(13.0)$ \\
\hline Urban & & & & $4318(38.0)$ \\
\hline Metropolitan & 13795 (31.6) & $519(39.6)$ & $1975(42.1)$ & \\
\hline $\begin{array}{l}\text { Metropolitan in proximity } \\
\text { to a medical school }\end{array}$ & $5516(12.6)$ & $228(17.4)$ & 781 (16.6) & $1756(15.4)$ \\
\hline
\end{tabular}

Data are presented as $\mathrm{n}(\%)$, unless otherwise stated.

Table 4.-Physician factors for hospitalised community-acquired pneumonia in Alberta during April 1, 1994-March 31, 1999

\begin{tabular}{|c|c|c|c|c|}
\hline Physician factors & $\begin{array}{l}\text { All pneumonia } \\
\text { hospital } \\
\text { discharges }\end{array}$ & $\begin{array}{c}\text { First } 72 \text {-h mortality } \\
\text { for pneumonia-hospital } \\
\text { discharges }\end{array}$ & $\begin{array}{c}\text { All in-hospital } \\
\text { mortality for } \\
\text { pneumonia hospital } \\
\text { discharges }\end{array}$ & $\begin{array}{c}\text { All-cause 1-yr } \\
\text { mortality for } \\
\text { pneumonia hospital } \\
\text { discharges }\end{array}$ \\
\hline Patients $\mathrm{n}$ & 43642 & 1311 & 4693 & 11370 \\
\hline $\begin{array}{l}\text { General/family practitioner listed } \\
\text { as most responsible physician }\end{array}$ & $31327(71.8)$ & $780(59.5)$ & $2815(60.0)$ & $7439(65.4)$ \\
\hline $\begin{array}{l}\text { Any internal medicine specialist or } \\
\text { subspecialist listed as consultant }\end{array}$ & $18325(42.0)$ & $621(47.4)$ & $2794(59.5)$ & $6064(53.3)$ \\
\hline \multicolumn{5}{|l|}{ Patient volume per in-hospital physician } \\
\hline 1st quartile & $12263(28.1)$ & $379(28.9)$ & $1334(28.4)$ & $3130(27.5)$ \\
\hline 4th quartile & $8377(19.2)$ & $291(22.2)$ & $1011(21.5)$ & $2390(21.0)$ \\
\hline $\begin{array}{l}\text { Pre-admission ambulatory visit by any } \\
\text { physician ( } 2-14 \text { days prior to admission date) }\end{array}$ & $18145(41.6)$ & $430(32.8)$ & $1650(35.2)$ & $4467(39.3)$ \\
\hline $\begin{array}{l}\text { Pre-admission ambulatory visit by an internal } \\
\text { medicine specialist or subspecialist } \\
\text { (2-14 days prior to admission date) }\end{array}$ & $2404(5.5)$ & $78(5.9)$ & $306(6.5)$ & $783(6.9)$ \\
\hline $\begin{array}{l}\text { Emergency room claim between } 2-14 \text { days } \\
\text { prior to admission date }\end{array}$ & $3910(9.0)$ & $102(7.8)$ & $374(8.0)$ & $955(8.4)$ \\
\hline
\end{tabular}

Data are presented as n (\%), unless otherwise stated.

grouped into quartiles (first quartile: $0-6$ patients $\cdot \mathrm{yr}^{-1}$; second quartile: $7-13$ patients $\cdot \mathrm{yr}^{-1}$; third quartile: $14-27$ patients $\cdot \mathrm{yr}^{-1}$; and fourth quartile: $>27$ patients $\cdot \mathrm{yr}^{-1}$ ). Mortality was proportionally greater in those without a physician consultation 2-14 days prior to admission. Physician consultations prior to hospitalisation were for the diagnosis of pneumonia $(7 \%)$, all respiratory diseases $(17 \%)$ and all other diagnosis $(76 \%)$. Mortality was proportionally greater in those admitted directly from the emergency room, but not in those with an emergency visit 2-14 days prior to admission.

Internal medicine specialists or subspecialists and highvolume physicians cared for patients with greater severity of presentation and more comorbidity (table 5). Similarly, preadmission consults by internal medicine specialists or subspecialists (but not for general practice physicians) occurred in patients with greater severity of presentation and more comorbidity. General practice physicians constituted 84,88 , 80 and $19 \%$, respectively, of each of the four physician volume quartiles (from low-to-high volume, respectively).

The c-statistics for pneumonia mortality models ranged $0.77-0.79$, where a value of 1 describes perfect prediction and 0.5 describes prediction no better than by chance (tables $6-8$ )
[18]. The patient factor group provided the best prediction of the mortality probabilities within $72 \mathrm{~h}$, in terms of model entry order and c-statistic. Physician factors associated with decreased mortality within $72 \mathrm{~h}$ were a nonspecialist, most responsible physician and specialist consult (during or prior to admission). None of the hospital-care organisation factors were significant.

Similar results were noted for all in-hospital deaths, with respect to patient factors (table 7). In this case, physician factors demonstrated decreased in-hospital mortality, with higher patient volumes for the most responsible physicians. Consults with an internal medicine specialist/subspecialist prior to admission were still associated with decreased inhospital mortality, but in-hospital consultation was associated with increased in-hospital mortality. Compared with the patient factor group, the physician factor group provided less power of model prediction in terms of model-entry order and c-statistic. Healthcare organisation factors (timing of admission) became significant in predicting in-hospital death.

Patient factors provided the greatest power of prediction for 1-yr mortality of those discharged from hospital (table 8). In-hospital specialist/subspecialist and high-volume physicians 
Table 5. - Relationship between severity of illness, comorbidity and physicians for community-acquired pneumonia in Alberta during April 1, 1994-March 31, 1999

\begin{tabular}{|c|c|c|c|}
\hline Characteristics & Patients & Comorbidity & Severity of presentation \\
\hline Patient volume per in-hospital physician < 7 (1st quartile) & $12263(28)$ & $1.01 \pm 1.07$ & $0.15 \pm 0.49$ \\
\hline Patient volume per in-hospital physician 7-13 (2nd quartile) & $12408(28)$ & $1.04 \pm 1.08$ & $0.13 \pm 0.46$ \\
\hline Patient volume per in-hospital physician $14-17$ (3rd quartile) & $10594(24)$ & $1.01 \pm 1.08$ & $0.14 \pm 0.47$ \\
\hline Patient volume per in-hospital physician $28+$ (4th quartile) & $8377(19)$ & $1.25 \pm 1.19$ & $0.31 \pm 0.69$ \\
\hline \multicolumn{4}{|l|}{ General/family practitioner as most responsible physician } \\
\hline Yes & $31327(71.8)$ & $0.98 \pm 1.05$ & $0.08 \pm 0.32$ \\
\hline No & $12315(28.2)$ & $1.29 \pm 1.19$ & $0.41 \pm 0.81$ \\
\hline \multicolumn{4}{|l|}{ Any internal medicine specialist or subspecialist listed as consultant } \\
\hline Yes & $18325(42.0)$ & $1.38 \pm 1.20$ & $0.33 \pm 0.72$ \\
\hline No & $25317(58)$ & $0.83 \pm 0.97$ & $0.06 \pm 0.27$ \\
\hline \multicolumn{4}{|c|}{ Pre-admission consult by internal medicine or subspecialist consultant } \\
\hline Yes & $2404(5.5)$ & $1.31 \pm 1.14$ & $0.24 \pm 0.61$ \\
\hline No & $41238(94.5)$ & $1.05 \pm 1.10$ & $0.17 \pm 0.52$ \\
\hline \multicolumn{4}{|l|}{ Pre-admission consult by any physician } \\
\hline Yes & $18145(41.6)$ & $1.07 \pm 1.10$ & $0.16 \pm 0.50$ \\
\hline No & $25497(58.4)$ & $1.06 \pm 1.10$ & $0.18 \pm 0.54$ \\
\hline
\end{tabular}

Data are presented as $n(\%)$ or mean \pm SD.

Table 6.-Logistic analysis for hospital death within the first $72 \mathrm{~h}$ of admission

\begin{tabular}{|c|c|c|}
\hline $\begin{array}{l}\text { Factor } \\
\text { group }\end{array}$ & Factor & $\begin{array}{c}\text { OR } \\
(95 \% \mathrm{CI})\end{array}$ \\
\hline \multicolumn{3}{|l|}{ Patient } \\
\hline \multirow[t]{3}{*}{$\begin{array}{l}\text { Severity } \\
\text { of illness }\end{array}$} & $\begin{array}{l}\text { Transfer to hospital from } \\
\text { continuing care }\end{array}$ & $\begin{array}{c}2.5 \\
(2.0-3.3)\end{array}$ \\
\hline & $\begin{array}{l}\text { Transfer to hospital by } \\
\text { ambulance }\end{array}$ & $\begin{array}{c}1.8 \\
(1.5-2.2)\end{array}$ \\
\hline & Emergent admission & $\begin{array}{c}2.0 \\
(1.7-2.5)\end{array}$ \\
\hline \multirow[t]{3}{*}{ Comorbidity } & $\mathrm{n}=1$ & $\begin{array}{c}1.9 \\
(1.4-2.5)\end{array}$ \\
\hline & $\mathrm{n}=2$ & $\begin{array}{c}2.2 \\
(1.6-3.1)\end{array}$ \\
\hline & $\mathrm{n}>2$ & $\begin{array}{c}3.0 \\
(2.1-4.3)\end{array}$ \\
\hline \multirow[t]{2}{*}{ Physician } & $\begin{array}{l}\text { With general practice/family } \\
\text { physician as most responsible } \\
\text { hospital physician }\end{array}$ & $\begin{array}{c}0.35 \\
(0.27-0.47)\end{array}$ \\
\hline & $\begin{array}{l}\text { With internal medicine or } \\
\text { subspecialist in-hospital } \\
\text { consultant }\end{array}$ & $\begin{array}{c}0.45 \\
(0.34-0.60)\end{array}$ \\
\hline \multirow[t]{4}{*}{ Age yrs } & $45-64$ & $\begin{array}{c}2.4 \\
(1.4-4.1)\end{array}$ \\
\hline & $65-74$ & $\begin{array}{c}2.5 \\
(1.5-4.1)\end{array}$ \\
\hline & $75-84$ & $\begin{array}{c}2.4 \\
(1.4-4.0)\end{array}$ \\
\hline & $85+$ & $\begin{array}{c}3.4 \\
(2.0-5.8)\end{array}$ \\
\hline Sex & Female & $\begin{array}{c}0.81 \\
(0.66-0.98)\end{array}$ \\
\hline Physician & $\begin{array}{l}\text { Pre-admission ambulatory } \\
\text { visit by an internal } \\
\text { medicine or } \\
\text { subspecialist consultant }\end{array}$ & $\begin{array}{c}0.55 \\
(0.31-0.96)\end{array}$ \\
\hline
\end{tabular}

Data are presented as odds ratio (OR) $(95 \%$ confidence interval $(\mathrm{CI}))$. The c-statistic is 0.768 for the model, 0.749 for patient factors alone and 0.579 and physician factors alone. No healthcare organisational factors were significant. The order of factors indicates the relative strength of the explanatory power. Each independent variable OR has been adjusted for the effects of the other variables. ${ }^{\#}$ : reference group is no comorbidity; $\uparrow$ : reference group aged $18-44$ yrs. were associated with increased mortality. Healthcare organisation factors were significant but had the least predicting power of death within a year. Hospital admission, not region of residence, was associated with increased mortality, while admissions to larger volume or metropolitan hospitals were associated with decreased mortality.

\section{Discussion}

This study explored the association of mortality with patient factors, physician factors and healthcare organisation factors after admission to hospital with CAP. Mortality rates of $11 \%$ occurred in hospital and $26 \%$ at 1 yr [3]. As expected, severity of illness and comorbidity had the strongest association with mortality [22]. This paper is the first study associating high-volume physician care with decreased inhospital mortality for CAP. The presence of an internal medicine specialist/subspecialist was not consistently associated with decreased hospital mortality except when a preadmission consultation occurred. Healthcare organisation factors were weakly associated with in-hospital mortality for the acute episode and mortality in those that were discharged after the initial index episode of pneumonia. One-year mortality was decreased in high-volume hospitals, where the original admission occurred.

The relationships between specialists/subspecialists, highvolume practice and more complex (greater severity of illness and comorbidity) patients are not easily separable. Specialists/ subspecialists practice in higher volume centres and see the more complex patients on referrals. Thus, any remaining confounding, due to patient selection bias towards severe illness/comorbidity, would tend to lower mortality associated with general practice physicians, while it increases mortality associated with specialists/subspecialists and high-volume physicians.

Randomised trials comparing high/low volume and general/ specialist practice are logistically difficult considering the need for large sample sizes to detect the small effects of practice and need to locate geographical areas where such a mix of physicians exist. Administrative-database studies capture the full spectrum of practices and patients, with sufficient sample size to demonstrate an effect. This study does not support the contention that in-hospital specialist/subspecialist care resulted in a unique mortality advantage. However, it is 
Table 7. - Logistic analysis for in-hospital death

\begin{tabular}{|c|c|c|}
\hline Factor group & Factor & OR $(95 \% \mathrm{CI})$ \\
\hline \multicolumn{3}{|l|}{ Patient } \\
\hline \multirow[t]{3}{*}{ Comorbidity } & $\mathrm{n}=1^{\#}$ & $2.4(1.9-2.8)$ \\
\hline & $\mathrm{n}=2^{\#}$ & $4.2(3.5-5.1)$ \\
\hline & $\mathrm{n}>2^{\#}$ & $5.9(4.8-7.3)$ \\
\hline Severity of illness & Transfer to hospital by ambulance & $1.8(1.6-2.0)$ \\
\hline \multicolumn{3}{|l|}{ Patient } \\
\hline \multirow[t]{4}{*}{ Age yrs } & $45-64$ & $2.1(1.5-2.9)$ \\
\hline & $65-74$ & $2.6(1.9-3.6)$ \\
\hline & $75-84$ & $2.8(2.1-3.9)$ \\
\hline & $85+$ & $4.5(3.3-6.2)$ \\
\hline \multirow[t]{2}{*}{ Severity of illness } & Transfer to hospital from continuing care & $1.8(1.5-2.0)$ \\
\hline & Emergent admission from home/office/clinic & $1.4(1.2-1.5)$ \\
\hline Physician & $\begin{array}{l}\text { With general practice/family physician as most } \\
\text { responsible hospital physician }\end{array}$ & $0.58(0.49-0.68)$ \\
\hline \multirow{4}{*}{$\begin{array}{l}\text { Patient volume per } \\
\text { in-hospital physician }\end{array}$} & $7-13^{+}$ & $0.85(0.73-0.99)$ \\
\hline & $14-27^{+}$ & $0.91(0.77-1.1)$ \\
\hline & $28+^{+}$ & $0.59(0.49-0.72)$ \\
\hline & With pre-admission consult by any physician & $0.79(0.70-0.89)$ \\
\hline \multirow[t]{2}{*}{ Patient } & Female & $0.81(0.72-0.91)$ \\
\hline & Aboriginal treaty status & $0.66(0.46-0.92)$ \\
\hline \multicolumn{3}{|c|}{ Healthcare organisation factor } \\
\hline \multirow[t]{2}{*}{ Admission } & December 1-March 31 & $0.85(0.75-0.95)$ \\
\hline & $18: 00-08: 00 \mathrm{~h}$ & $0.84(0.75-0.95)$ \\
\hline Physician & Internal medicine specialist or subspecialist in-hospital consultant & $1.23(1.1-1.43)$ \\
\hline
\end{tabular}

Data are presented as odds ratio (OR) $(95 \%$ confidence interval (CI)). The c-statistic is 0.789 for the model, 0.780 for patient factors alone, 0.626 for physician factors alone and 0.517 for healthcare organisational factors alone. The order of factors indicate the relative strength of the explanatory power. Each independent variable OR has been adjusted for the effects of the other variables. ${ }^{\#}$ : reference group is no comorbidity; ${ }^{\uparrow}$ : reference group aged 18-44 yrs; ${ }^{+}$: reference group is patient volume per physician (1st quartile).

Table 8. - Logistic analysis for death at $1 \mathrm{yr}$ excluding all in-hospital deaths

\begin{tabular}{|c|c|c|}
\hline Factor group & Factor & OR $(95 \% \mathrm{CI})$ \\
\hline \multicolumn{3}{|l|}{ Patient } \\
\hline Severity of illness & Transfer to hospital from continuing care & $2.3(2.0-2.7)$ \\
\hline \multirow[t]{3}{*}{ Comorbidity } & $\mathrm{n}=1^{\#}$ & $2.2(1.9-2.5)$ \\
\hline & $\mathrm{n}=2^{\#}$ & $3.5(3.0-4.1)$ \\
\hline & $\mathrm{n}>2^{\#}$ & $4.8(4.0-5.7)$ \\
\hline \multirow[t]{4}{*}{ Age yrs } & $45-64$ & $2.6(2.0-3.3)$ \\
\hline & $65-74$ & $2.9(2.3-3.8)$ \\
\hline & $75-84$ & $4.0(3.2-5.1)$ \\
\hline & $85+\mathrm{yrs}$ & $5.8(4.5-7.4)$ \\
\hline Sex & Female & $0.66(0.60-0.73)$ \\
\hline Physician & With internal medicine or subspecialist in-hospital consultant & $1.5(1.27-1.68)$ \\
\hline \multicolumn{3}{|c|}{ 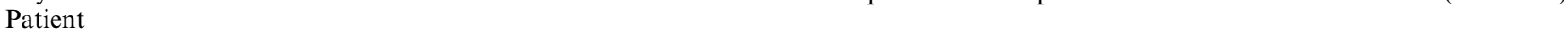 } \\
\hline Severity of illness & Transfer to hospital by ambulance & $1.4(1.2-1.5)$ \\
\hline Healthcare organisation factor & Patient residence region different from hospital & $1.4(1.2-1.6)$ \\
\hline Admission & December 1-March 31 & $0.82(0.74-0.91)$ \\
\hline Physician & $\begin{array}{l}\text { With pre-admission consult by internal medicine } \\
\text { specialist or subspecialist consultant }\end{array}$ & $1.31(1.1-1.6)$ \\
\hline \multirow{3}{*}{$\begin{array}{l}\text { Patient volume per } \\
\text { in hospital physician }\end{array}$} & $7-13^{+}$ & $1.0(0.89-1.2)$ \\
\hline & $14-27^{+}$ & $1.2(1.0-1.3)$ \\
\hline & $28+^{+}$ & $1.0(0.84-1.1)$ \\
\hline \multirow[t]{4}{*}{ Healthcare organisation factor } & Admission to rural hospital $\left(50-108 \text { cases } \cdot \mathrm{yr}^{-1}\right)^{\S}$ & $0.91(0.77-1.1)$ \\
\hline & Admission to regional hospital ${ }^{\S}$ & $0.74(0.61-0.89)$ \\
\hline & Admission to urban hospital (metropolitan) ${ }^{\S}$ & $0.83(0.70-0.99)$ \\
\hline & $\begin{array}{l}\text { Admission to urban hospital (hospitals in } \\
\text { proximity to a medical school metropolitan) }\end{array}$ & $0.95(0.77-1.2)$ \\
\hline \multicolumn{3}{|c|}{ 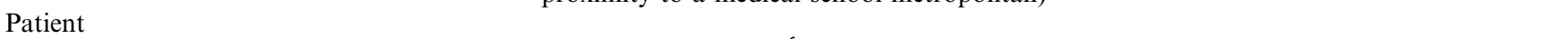 } \\
\hline Severity of illness & Severity of presentation ${ }^{f}$ & $1.2(1.1-1.4)$ \\
\hline Healthcare organisation factor & Holiday & $0.84(0.75-0.95)$ \\
\hline
\end{tabular}

Data are presented as odds ratio (OR) $(95 \%$ confidence interval (CI)). The c-statistic is 0.768 for the model, 0.763 for patient factors alone, 0.578 for physician factors alone and 0.569 for healthcare organisational factors alone. The order of factors indicates the relative strength of the explanatory power. Each independent variable OR has been adjusted for the effects of the other variables. ${ }^{\#}$ : reference group is no comorbidity; ${ }^{\uparrow}$ : reference group aged 18-44 yrs; ${ }^{+}$: reference group is patient volume per physician (1st quartile); ${ }^{\S}$ : reference group is rural hospitals of $\left(<50\right.$ cases $\left.\cdot \mathrm{yr}^{-1}\right) ;{ }^{f}:$ defined in methods. 
supportive of an advantage for high-volume practice. Many studies addressing the relationship between volume of procedures and patient outcomes have been published, most with respect to surgical care [23-25]. Similar to the current study, hospital size or the physician volume was used as a proxy for physician skill. CAP, unlike surgical volume studies, is not associated with a unique procedure or skill. Treatment of pneumocystis pneumonia in human immunodeficiency virus-seropositive patients has been associated with improved outcomes when treated in higher volume centres [26]. Among studies analysing hospital volumes and outcomes, better outcomes have been associated with higher patient volumes in some instances [27-30], but not others [28, $31,32]$. Some studies of individual-provider volume have shown a positive relationship between volume and outcomes $[33,34]$, whereas others have shown no relation or inconsistent results [23, 35]. Finally, only a few studies similar to the current study have analysed both hospital volume and provider volume and reported a positive volume/outcome relation $[36,37]$.

This study does not specify which aspects of high-volume care may be associated with decreased mortality. Specialist/ subspecialist evaluation and treatment may be better because of greater conformity to published guidelines [38, 39]. It is not known if high-volume practice conforms to treatment guidelines for CAP. Early physician care documented as a preadmission visit was associated with decreased in-hospital mortality, suggesting that expedient medical care is an important component of a care pathway for CAP [2]. Physicians were specified as the clinician involved with highvolume practice. Other healthcare workers may also become more skilled where high-volume practice is supported. However, hospital volume itself was not associated with lower mortality. The current study, unlike others [40], did not find any association with decreased mortality, at a time when hospital staffing, including consultants, allied healthcare specialties and management, may be more limited (weekends and holidays, 18:00-08:00 h). Another possible advantage to high-volume care or pre-admission consultation is timely, appropriate, antibiotic administration [41, 42]. Finally, highvolume practitioners may simply be better able to anticipate problems, rather than react postoccurrence. The ability to emulate high-volume practice may represent another strategy to help physicians follow practice guidelines [43]. This may be particularly important since most cases of hospitalised pneumonia are cared for by primary-care physicians in community hospitals [44]. This study does not specify why some of the hospital organisation factors were associated with decreased mortality for CAP mortality. The benefit of high-volume hospitals may be related to better aftercare in the old and frail, which are at greater risk of death, rather than the specific treatment of the actual pneumonia.

The current study has several limitations. Pneumonia may exacerbate a pre-existing comorbidity. The authors did not know which came first (i.e. the pneumonia made the comorbidity worse or the comorbidity became worse and pneumonia ensued). As the patient cohort was older, almost all patients had a least one comorbidity. The authors do not believe the data was sufficiently detailed to accurately and reliably identify all internal medicine subspecialties as distinct from internal medicine speciality. This is especially true as some physicians have multiple-board certification and the physician reimbursement rules sometimes result in the same individual physician using different specialty designation. Data from the current study was sufficiently robust to identify specialists/subspecialists from nonspecialists, since this indicator has important financial implications for both the practitioner and hospital.

Population-based administrative database research may be highly generalised, although limited in clinical details. The authors attempted to adjust for case severity and comorbidity, but may not have captured all variation [45]. These variables are likely to be less reliable than a clinically derived pneumonia index [2]. Processes of care variables, such as use of a special/intensive care unit or transfer to another hospital, are not justified by a specific threshold. As such, these variables would be expected to vary widely between patients and hospitals. Despite these limitations, the model's overall prediction of mortality was good as demonstrated by the c-statistic. The authors were not able to uniquely identify physicians who practiced in more than one hospital. Therefore, combined case volumes could not be credited to these multi-institutional physicians.

\section{References}

1. Feagan BC, Marrie TJ, Lau CY, Wheeler SL, Wong CJ, Vandervoort MK. Treatment and outcomes of communityacquired pneumonia at Canadian hospitals. CMAJ 2000; 162: 1415-1420.

2. Marrie TJ, Lau CY, Wheeler SL, Wong CJ, Vandervoort MK, Feagan BG. A controlled trial of a critical pathway for treatment of community-acquired pneumonia. JAMA 2000; 283: 749-755.

3. Fine M, Hough L, Medsger A, et al. The hospital admission decision for patients with community-acquired pneumonia. Arch Intern Med 1997; 157: 36-44.

4. Fine M, Medsger A, Stone RA, et al. The hospital discharge decision for patients with community-acquired pneumonia. Arch Intern Med 1997; 157: 47-56.

5. Fine MJ, Auble TE, Yealy DM, et al. A prediction rule to identify low-risk patients with community-acquired pneumonia. $N$ Engl J Med 1997; 336: 243-250.

6. Rhew DC, Riedinger MS, Sandhu M, Bowers C, Greengold $\mathrm{N}$, Weingarten SR. A prospective, multicenter study of a pneumonia practice guideline. Chest 1998; 114: 115-119.

7. Ewig S, Kleinfeld T, Bauer T, Seifert K, Schafer H, Goke N. Comparative validation of prognostic rules for communityacquired pneumonia in an elderly population. Eur Respir $J$ 1999; 14: 370-375.

8. Dean NC, Silver MP, Bateman KA, James B, Hadlock CJ, Hale DH. Decreased mortality after implementation of a treatment guideline for community-acquired pneumonia. $\mathrm{Am}$ $J$ Med 2001; 110: 451-457.

9. Feagan BC, Marrie TJ, Lau CY, Wheeler SL, Wong CJ, Vandervoort MK. Treatment and outcomes of communityacquired pneumonia at Canadian hospitals. CMAJ 2000; 162: $1415-1420$

10. Healthcare Financing Administration. Inpatient Management of Pneumonia in Medicare Beneficiaries; Ten Western States, Fiscal Year 1993. Seattle, Healthcare Financing Administration, 1996.

11. Meehan TP, Fine MJ, Krumholz HM, et al. Quality of care, process, and outcomes in elderly patients with pneumonia. JAMA 1997; 278: 2080-2084.

12. Hand R, Pointek F, Klemka-Walden L, Incauskis D. Use of statistical control charts to assess outcomes of medical care. Am J Med Sci 1994; 307: 329-334.

13. Draper D, Kahn KL, Reinisch EJ, et al. Studying the effects of the DRG based prospective payment system on quality of care. JAMA 1990; 264: 1956-1961.

14. Marrie TJ, Durant H, Sealy E. Pneumonia - the quality of medical records. Medical Care 1987; 25: 20-24.

15. Canada Government Health Division, Nosology Reference Centre, Minister of Supply and Services. Canadian Classification of Diagnostic, Therapeutic, and Surgical Procedures. Ottawa, Canada Government Health Division, 1986.

16. Deyo RA, Cherkin DC, Ciol MA. Adapting a clinical 
comorbidity index for use with ICD-9-CM administrative databases. J Clin Epidemiol 1992; 45: 613-619.

17. Romano PS, Roos LL, Jollis JG. Adapting a clinical comorbidity index for use with ICD-9-CM administrative data: differing perspectives. J Clin Epidemiol 1993; 46: 1075-1079.

18. Iezzoni LI. Risk adjustment for measuring healthcare outcomes. In: Health. 2nd Edn. Chicago, Administration Press, 1998; pp. 432-443.

19. Seber GAF. Linear Regression Analysis. New York, Wiley, 1977.

20. Hosmer DW, Lemeshow S. Applied Logistic Regression. New York, Wiley, 1989.

21. Cree M, Roos N, Yang Q, Carriere K. Hypertensive patients and their general practitioners. Health Manage Forum 2001; 14: 33-40.

22. Fine JM, Smith MA, Carson CA, et al. Prognosis and outcomes of patients with community-acquired pneumonia. JAMA 1996; 275: 134-141.

23. Luft HS, Bunker JP, Enthoven AC. Should operations be regionalized? The empirical relation between surgical volume and mortality. N Engl J Med 1979; 301: 1364-1369.

24. Hillner BE, Smith TJ, Desch CE. Hospital and physician volume or specialization and outcomes in cancer treatment: importance in quality of cancer care. J Clin Oncol 2000; 18: 2327-2340.

25. Shackley P, Slack R, Booth A, Michaels J. Is there a positive volume-outcome relationship in peripheral vascular surgery? Results of a systematic review. Eur J Vasc Endovasc Surg 2000; 20: 326-335.

26. Bennett CL, Garfinkle JB, Greenfield S, et al. The relation between hospital experience and in-hospital mortality for patients with AIDS-related PCP. JAMA 1989; 261: 29752979.

27. Nathens AB, Jurkovich GJ, Maier RV, Grossman DC, Mackenzie EF, Moore M. Relationship between trauma center volume and outcomes. JAMA 2001; 285: 1164-1171.

28. Theimann DR, Coresh J, Oetgen WJ, Powe NR. The association between hospital volume and survival after acute myocardial infarction in elderly patients. $N$ Engl $J$ Med 1999; 34: 1640-1648.

29. Begg CG, Cramer LD, Hoskins WJ, Brennan MF. Impact of hospital volume on operative mortality for major cancer surgery. JAMA 1998; 280: 1747-1751.

30. Schrag D, Cramer LD, Bach PB, Cohen AM, Warren JL, Begg $\mathrm{CB}$. Influence of hospital procedure volume on outcomes following surgery for colon cancer. JAMA 2000; 284: $3028-3035$.

31. Simunovic M, To T, Baxter N, Balshem A, Ross E, Cohen Z. Hospital procedure volume and teaching status do not influence treatment and outcome measures of rectal cancer surgery in a large general population. J Gastrointest Surg 2000; 4: 324-330.

32. Maynard C, Every NR, Chapko MK, Ritchie JL. Outcome of coronary angioplasty procedures performed in rural hospitals. Am J Med 2000; 108: 710-713.

33. Tu JV, Austin PC, Chan BT. Relationship between annual volume of patients treated by admitting physicians and mortality after acute myocardial infarction. JAMA 2001; 285: 3116-3122.

34. Kreder HJ, Deyo RA, Koespell T, Swiontkowski MF, Kreuter W. Relationship between the volume of total hip replacements performed by providers and rate of postoperative complications in the state of Washington. $J$ Bone Joint Surg Am 1997; 79: 485-494.

35. Hodgson DC, Fuchs CS, Ayanian JZ. Impact of patient and provider characteristics on the treatment outcomes of colorectal cancer. J Natl Cancer Inst 2001; 93: 501-515.

36. McGrath PD, Wennberg DE, Dickens JD, Siewers AE, Lucas FL, Alenka DJ. Relationship between operator and hospital volume and outcomes following percutaneous coronary intervention in the era of the coronary stent. JAMA 2000; 284: 3139-3144.

37. Gordon TA, Bowman HM, Bass EB, Lillemoe KD, Yeo CJ, Heitmiller RF. Complex gastrointestinal surgery: impact of provider experience on clinical and economic outcomes. $\mathrm{J} \mathrm{Am}$ Coll Surg 1999; 189: 46-56.

38. Auerbach AD, Hamel MB, Davis RB, et al. Resource use and survival of patients hospitalized with congestive heart failure: differences in care by specialty of the attending physician. SUPPORT Investigators. Study to Understand Prognoses and Preferences for Outcomes and Risks of Treatments. Ann Intern Med 2000; 132: 191-200.

39. Auerbach AD, Hamel MB, Califf RM, et al. Patient characteristics associated with care by a cardiologist among adults hospitalized with severe congestive heart failure. SUPPORT Investigators. Study to Understand Prognoses and Preferences for Outcomes and Risks of Treatments. $J$ Am Coll Cardiol 2000; 36: 2119-2125.

40. Bell CM, Redelmeirer DA. Mortality among patients admitted to hospitals on weekends as compared to weekdays. $N$ Engl J Med 2001; 345: 663-668.

41. Miletin MS, Chan CK. The use of guidelines for the empirical treatment of hospital-acquired pneumonia. Can Respir $J$ 2001; 8: 255-260.

42. Gleason PP, Meehan TP, Fine JM, Galusha DH, Fine MJ Associations between initial antimicrobial therapy and medical outcomes for hospitalized elderly patients with pneumonia. Arch Intern Med 1999; 159: 2562-2572.

43. Englert J, Davis KM, Koch KE. Using clinical practice analysis to improve care. Jt Comm J Qual Improv 2001; 27: 291-301.

44. Dean NC, Silver MP, Bateman KA. Frequency of subspecialty physician care for elderly patients with communityacquired pneumonia. Chest 2000; 117: 393-397.

45. Ewig S, Ruiz M, Mensa J, et al. Severe community-acquired pneumonia. Assessment of severity criteria. Am J Respir Crit Care Med 1998; 158: 1102-1108. 